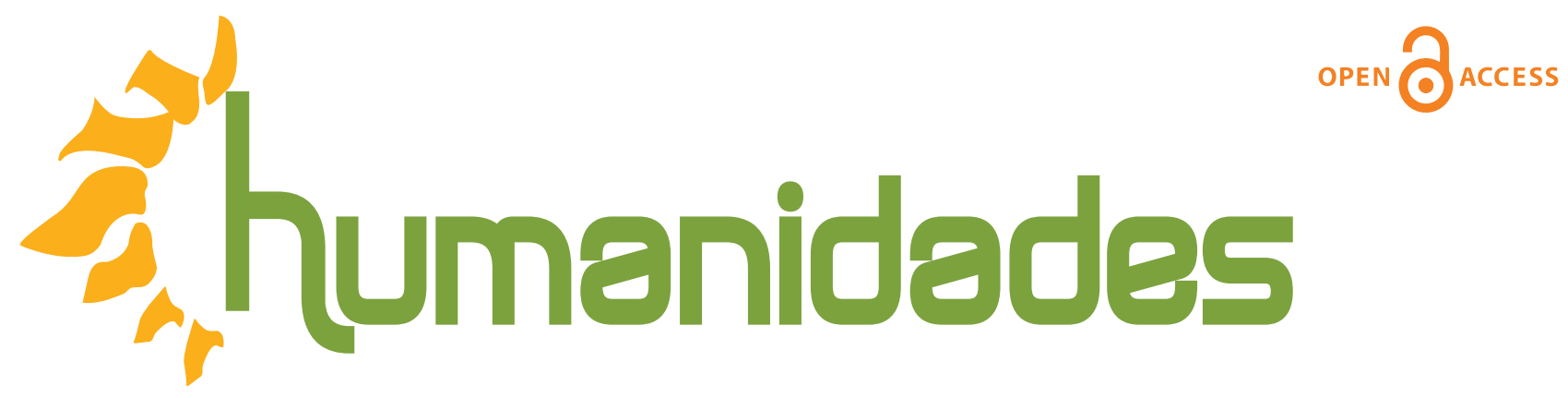

Revista de la Escuela de Estudios Generales, Universidad de Costa Rica

Julio-diciembre, 2019 •Volumen 9, número 2 • EISSN 2215-3934 • pp. 1-17

Recibido: 27-Marzo-2019 Aceptado: 25-Abril-2019

\title{
Filosofía, tecnología y cultura en el discurso visual de la cinta 2001: una odisea del espacio
}

DOI: https://doi.org/10.15517/h.v9i2.37518

\section{María Esther Chamosa Sandoval}

Doctora en Estudios Transdisciplinarios de la Cultura y la Comunicación, Licenciada en

Ciencias de la Comunicación y Máster en Humanidades

Universidad Justo Sierra, México

Correo electrónico: mchamosa@ujsierra.com.mx / cinemarieth@gmail.com

\section{Alejandro Herrera González}

Máster en Humanidades, Licenciado en Ciencias de la Comunicación y tiene una Especialidad en Antropología Cultural

Universidad Justo Sierra, México

Correo electrónico: alexherrera@alephmultimedios.com / lextermaster@gmail.com

Todos los derechos reservados. Universidad de Costa Rica. Esta revista se encuentra licencida con Creative Commons. Reconocimiento-NoComercial-SinObraDerivada 3.0 Costa Rica. Correo electrónico: humanidades@ucr.ac.cr/ Sitioweb: http: //revistas.ucr.ac.cr/index.php/humanidades 


\section{Filosofía, tecnología y cultura en el discurso visual de la cinta 2001: una odisea del espacio}

\section{Resumen}

La película de Stanley Kubrick, 2001: una odisea del espacio es un buen punto de partida para explorar tres aspectos que parecieran inherentes a la problemática de la modernidad: la relación entre tecnología, cultura y discurso. La cinta estrenada en 1968 remite a una serie de subtextos en los cuales el director se pregunta sobre la existencia, el ser, el tiempo, la inteligencia artificial, la voluntad, la vida, la muerte y el renacimiento. Por ello, este trabajo tiene como propósito abordar el complejo espectro representado en la conocida odisea intergaláctica para generar una posible respuesta a la pregunta ¿cómo se entretejen, en el argumento audiovisual del filme, los panoramas filosóficos que revelan una interconexión entre cultura y tecnología para la elaboración de un discurso que pone en evidencia la doble articulación del término evolución como mecanismo creador de lo humano y, al mismo tiempo, como artífice de su destrucción? Dicha pregunta nos lleva al siguiente esbozo hipotético: 2001: una odisea del espacio revela una relación entre cultura y tecnología para la elaboración de un discurso que pone en evidencia la doble articulación del término evolución como mecanismo creador de lo humano y, a la vez, como artífice de su destrucción.

\section{Philosophy, Technology and Culture in the Visual Discourse of the Film 2001: A Space Odyssey}

\begin{abstract}
Stanley Kubrick's film, 2001: A Space Odyssey, explores the relationship between technology, culture and discourse. The film, premiered in 1968, refers to subtexts in which the director asks about existence, being, time, artificial intelligence, will, life, death and rebirth. Therefore, this paper seeks to address the complex spectrum represented in the well-known intergalactic odyssey to generate a possible answer to the questions: How are the philosophical panoramas that reveal an interconnection between culture and technology interwoven in the audiovisual argument of the film? How do culture and technology relate to the term evolution as a creative mechanism of the human and, at the same time, as the architect of its destruction? These questions could be answered with the following hypothesis: 2001: A Space Odyssey reveals a relationship between culture and technology for the elaboration of a discourse that highlights the double articulation of the term evolution as a mechanism that creates the human and at the same time, as the architect of its destruction.
\end{abstract}

Palabras clave:

evolución, cultura, ciencia, tecnología, cine

Keywords:

evolution, culture, science, technology, cinema 
Filosofía, tecnología y cultura...

\section{Introducción}

Como mencionan Marshall y Eric McLuhan en Leyes de los medios (1990), los griegos tenían dos vocablos para designar "palabra" o "locución", una era logos y la otra mythos. La primera, la más antigua, funcionaba en las sociedades orales como una suerte de tecnología a partir de la cual se establecían vínculos comunicativos, pero también servía como un vehículo para forjar y transmitir la cultura. De acuerdo con los autores, el logos era, antes de la escritura, activo y metamórfico, es decir, poseía una función creativa, pues “decir” estaba relacionado con la capacidad de hacer y transformar.

Si bien es cierto que hace aproximadamente 7000 años, con el surgimiento de la escritura, el ser humano dejó las primeras muestras de su dominio del lenguaje, también resulta innegable que el habla es mucho más antigua. Las evidencias científicas recientes muestran que el lenguaje, tal y como lo conocemos hoy en día, fue consecuencia de un salto evolutivo que derivó, no solamente, en la verbalización del entorno, sino en un proceso que pretendía mimetizar la naturaleza y la vida cotidiana, como puede apreciarse en las expresiones pictóricas de Altamira. La nueva dimensión simbólica del hombre le dio acceso a un universo cognitivo con el cual le fue posible ya no solo habitar el mundo, sino pensarlo.

Este "pensar" reafirmaría lo que Heidegger denomina como la consumación del ser en la esencia del hombre, pues "habla" y "pensamiento" serían, desde aquel momento en adelante, el instrumento para reconocerse en el otro. Esta proyección ontológica posibilitó no solamente el surgimiento de nuevas estructuras de organización más allá de lo biológico, con las cuales se hizo necesaria la inclusión de herramientas que ayudaran, no solo a modelar y reconstruir la naturaleza para adaptarla a las necesidades de la especie, sino que funcionaran también como una narrativa que diera coherencia a la naciente e inseparable relación entre la conceptualización de la esfera inmediata y su inminente reconfiguración a partir de la técnica. 
La escritura, efecto derivado de diversas adaptaciones epistemológicas, implementó por vez primera la noción del ser histórico, aquel capaz de proyectar no solamente, siguiendo el principio de McLuhan (1996), las extensiones de su cuerpo físico, sino también las de su corpus mental e imaginario para perpetuar su permanencia en el tiempo. La capacidad de ficcionar, de fingir, de reconstruir lo inmediato, no en el plano físico sino en el texto, es sin lugar a dudas una de las características más notables de la especie humana. El impulso constante del relato oral para definir quiénes somos, de dónde venimos y hacia dónde vamos, actualmente podría parecer remoto, pues hemos atestiguado el desarrollo de técnicas y tecnologías a partir de las cuales este proceso de "contar" y reafirmar nuestro devenir social, cultural y antropológico, se hace presente reconfigurando la realidad.

El cine es un decoroso ejemplo de lo anterior, la pantalla nos confronta con ese "Gran Otro" que nos muestra lo que yace oculto, lo que no se ve a simple vista y requiere una exégesis profunda para llegar a lo que los griegos denominaban aleteia (verdad), pero no una verdad absoluta, totémica, sino una que saque a la luz, transforme y conmute el sentido de nuestra existencia. El cine, con su montaje escénico, sus diálogos que emulan el arte de la conversación; el cine y sus emplazamientos y movimientos de cámara que nos obliga a ver lo que en apariencia nos resulta conocido, cercano, pero desde una perspectiva intervenida, idealizada; es el punto de convergencia entre aquel logos y mythos griego, donde la palabra, a manera de demiurgo, urde el relato moderno sobre lo que fuimos, somos y pudiéramos llegar a ser.

Mencionar algún título específico para dar cuenta de lo antes dicho conllevaría una labor titánica e interminable, sin embargo, para los fines del presente escrito, la película de Stanley Kubrick, 2001: una odisea del espacio, es un buen punto de partida para retomar tres aspectos que parecieran inherentes a la problemática de la modernidad: la relación entre tecnología, cultura y discurso.

La cinta realizada en 1968 plantea, a simple vista, como si de una fábula precautoria se tratara, las implicaciones negativas que la máquina trae para el ser humano; primero, como un esbozo primitivo que remite al homo faber, y posteriormente, con la complicada ingeniería que se derivó de ese primer acercamiento muchos siglos después. 
Filosofía, tecnología y cultura...

Sin embargo, las implicaciones filosóficas del relato cinematográfico no remiten únicamente a lo inmediato, a lo que se percibe en un primer contacto, sino también a una serie de subtextos en los cuales el director se pregunta sobre la existencia, el ser, el tiempo, la inteligencia artificial, la voluntad, la vida, la muerte y el renacimiento.

Por ello, este trabajo tiene como propósito abordar el complejo espectro representado en la conocida odisea intergaláctica para generar una posible respuesta a la pregunta ¿cómo se entretejen, en el argumento audiovisual del filme, los panoramas filosóficos que revelan una interconexión entre cultura y tecnología para la elaboración de un discurso que pone en evidencia la doble articulación del término evolución como mecanismo creador de lo humano $\mathrm{y}$, al mismo tiempo, como artífice de su destrucción? Dicha pregunta nos lleva al siguiente esbozo hipotético: 2001: una odisea del espacio revela una relación entre cultura y tecnología para la elaboración de un discurso que pone en evidencia la doble articulación del término evolución como mecanismo creador de lo humano y, a la vez, como artífice de su destrucción.

Destaca la manera en la cual el cine nos ha presentado, a través de sus distintos géneros: la comedia, el drama o la ciencia ficción, podemos hallar las implicaciones ideológicas, psicológicas, antropológicas, filosóficas, etcétera, de los avances que, por medio de la ciencia, ha alcanzado el campo tecnológico. Obras como Frankenstein, basada en la novela de Mary Shelley, originalmente proyectada en 1931 y sus posteriores remakes, Demon Seed de 1977, Alien y hasta títulos más recientes como The Matrix o Resident Evil, han planteado cuestionamientos que reflejan las preocupaciones de la sociedad, de un lugar y momento histórico específicos, respecto a los alcances técnicos y las consecuencias sobre su uso.

En los 60, la última frontera se encontraba en el espacio exterior, 2001: una odisea del espacio muestra en su argumento la evolución de la ciencia y la tecnología como resultado de un devenir histórico lógico que hace referencia a la teoría de Darwin, pero también a una filosofía que se pregunta por el espíritu de la razón y el advenimiento del superhombre. 


\section{Evolución y cultura}

Edgar Morin (2009) define "humanización" como una interconexión tripartita conformada por el individuo, la especie y la sociedad. Sin esta relación, la evolución no sería posible. Si tomamos en cuenta esta postura, que en un estadio más avanzado propone una visión transdisciplinaria como metodología de trabajo para aproximarse a todo aquello que concierne al hombre y la naturaleza de este, se puede leer que dicha postura estaría marcada también por un origen que implica tres vertientes complejas: lo cosmogónico, lo filogenético y lo antropogenético.

$\mathrm{Si}$ entendemos la sociedad como un conjunto integrado por individuos asociados y consensuados, no puede resultarnos extraño el hecho de que, en algún punto del proceso evolutivo, los primeros humanos dejaron el espectro de la no conciencia para organizarse en lo que Maturana (2003) designa como "sistemas sociales". Dicha sistematización apareció cuando se presentó una relación estructural congruente entre seres vivos y el entorno, a través de una auto-organización o autopoiesis que conllevó a la elaboración de un cierto contexto-comunicativointeraccional.

La aparición del lenguaje detonó también otras dimensiones que nunca habían acontecido en la naturaleza. La idea del hombre como animal simbólico, político y, hoy en día, si se permite la expresión, como animal tecnológico, daría pie a una estructura compleja de percepción sobre la realidad en la cual la modificación del entorno ya no responde únicamente a la satisfacción de necesidades inherentes a la supervivencia de la especie, sino a marcas específicas cuyo significado va más allá de lo que se ve a simple vista. La herramienta, por ejemplo, deja de ser un objeto utilitario para convertirse en una señal de estatus, la vestimenta ya no solo sirve para protegerse de las inclemencias del tiempo, sino para separar jerarquías, y el uso de ciertas palabras se sacraliza y se pone a disposición de unos cuantos, quienes gozan del privilegio de invocar, incluso, lo intangible.

El nacimiento de la cultura se da a partir de la relación entre hombre, comunicación y trabajo. De acuerdo con las nociones revisadas por Kroeber y Kluckhohn (1959), "cultura" supone la acción de cultivar; de ahí que después se entendiera como la adquisición de conocimientos para el enriquecimiento del mundo íntimo. 
Filosofía, tecnología y cultura...

Sin embargo, los mismos autores llevan esta definición aún más lejos al manifestar que es imposible la separación entre cultura y civilización, pues la existencia de esta última, inherente solo a la especie humana, plantea la resolución de problemas sociales. El análisis y solución de estas problemáticas sociales están ligados, invariablemente, a la puesta en escena de la condición histórica que plantea el lenguaje, pero también en gran medida a la similitud biológica a partir de la cual la especie se reconoce en la esencia del otro.

\section{Ciencia y tecnología como construcciones culturales}

Resulta complicado a estas alturas tratar de hacer una distinción tajante entre cultura y ciencia, finalmente, como menciona Agustín Lage Dávila, "la cultura es conocimiento socialmente adquirido y socialmente compartido y transmitido" y a su vez, "el método científico es una adquisición de la cultura como forma de conocimiento" (Lage, 2001, p. 191). Sin embargo, las formas a partir de las cuales la ciencia valida el conocimiento se han transformado con el paso del tiempo, por ejemplo, los sucesores de Aristóteles se referían a la ciencia como "la comprensión segura, cierta e inmutable, o un hábito inmutable para acoger representaciones, fundado en la razón” (Abbagnano, 2000, p. 163). Hoy en día, esta categoría de inmutabilidad ya no es aceptable en el contexto científico, pues se ha reconocido el carácter variable de la sociedad y con ello la inmanente movilidad de la ciencia.

Para Mario Bunge, la ciencia es "la búsqueda crítica de pautas o la utilización de éstas en las ideas, la naturaleza o la sociedad" (Bunge, 2000, p. 22). En términos contemporáneos, la ciencia puede ser entendida como un proceso de investigación que brinda la posibilidad de obtener conocimientos, cuyo potencial está centrado en las nuevas posibilidades de manipulación sobre los diferentes fenómenos. Existe la posibilidad de atender sus impactos prácticos y productivos caracterizando a la ciencia como fuerza productiva que favorece la transformación del mundo; la ciencia, además de ser una construcción cultural, es presentada como una profesión categóricamente institucionalizada, poseedora de su propia cultura y con funciones sociales bien definidas. 
Por su parte, la tecnología también posee una entrañable naturaleza social, ya sea porque se da en el seno de las diversas comunidades o por su injerencia para la transformación de las mismas. La tecnología, en su sentido más sencillo, se refiere a aquel conocimiento práctico que, en ocasiones, emana directamente de la ciencia. La tecnología es la representación de cierta investigación cuyo producto principal es una máquina, un medicamento, un producto o un proceso. En la actualidad, la concepción de ciencia como conocimiento puro ha sido desplazada por una nueva visión que integra las diversas dimensiones del trabajo científico relacionadas con la técnica, aquello a lo que Heidegger denomina un medio para unos fines o un hacer del hombre.

Actualmente, el hombre inventa máquinas basadas en proyectos racionales sustentados en la nueva ciencia, abstracta, matematizada, cambiante y relativa, ocasionando una fusión innegable entre ciencia, comunicación y tecnología, disolviendo los clásicos límites atribuidos entre estas; pues el desarrollo técnico depende estrechamente de la ciencia y el progreso de la ciencia depende, por su parte, de la técnica; pero ambas, ciencia y tecnología, requieren, definitivamente, de la inmanente presencia-acompañamiento de la comunicación.

\section{Cine, reflejo de la cultura y del ser}

El hombre es capaz de percibir su propia existencia y humanidad en tanto es nombrado y reconocido por el otro. El recuerdo, ese mecanismo de imaginación a partir del cual, como en La invención de Morell, se permanece en el mundo como una entidad casi holográfica, instalada en instante del tiempo y el espacio, tiene una cercana relación con el cine. Dicha atracción, surgida como un entretenimiento de feria hace más de un siglo, se ha convertido en una suerte de espejo, un artilugio que nos interpreta y reinterpreta como un demiurgo que, a través del discurso, es capaz de contarnos lo que fuimos, somos o pudiéramos llegar a ser en lo colectivo.

Siguiendo la idea heiddegeriana sobre la técnica, no como una definición instrumental, sino como la causa eficiente de las cosas, podríamos decir que el cine es un aparato creado por el hombre para narrarse a sí mismo. 
Filosofía, tecnología y cultura...

Así, el cine funge como un escaparate ideal para el encuentro de las miradas, la del director, quien proporciona una visión sobre el mundo; la del personaje, que pone en escena una versión de lo humano y, el espectador, quien se alimenta y retroalimenta el universo que aparece en la pantalla para hacer una reconfiguración cognitiva o de la realidad.

El espectador se sabe humano en tanto se identifica con el ser, tiempo, hacer y estar de un personaje. Este encuentro entre ambos es cíclico; por un lado, el espectador se busca en los ojos de un otro yo (que no es más que una representación), al mismo tiempo que, por el otro, el personaje alcanza su existencia transitoria en tanto que logra parecerse al que le sigue de cerca, al que le escucha, le mira, le envidia o le añora; al que le nombra y le recuerda, al que le da la vida o se la quita, depende que tanto le cautive o le aterrorice al espectador el juego de espejos que brota del fenómeno cinematográfico. Es el cine un espacio para la coexistencia y el reflejo de la cultura, la comunicación y del ser.

No se es humano en ausencia de la humanidad. Es en el seno de la convivencia que florece y logra "ser" el hombre. Pensamiento y lenguaje humanizan el andar de los gregarios que eligieron la palabra para nombrar al mundo y a sí mismos. Pensamiento y lenguaje dan vida humana al hombre verdadero y al hombre re-presentado por el cine. Hay incontables similitudes entre la vida y el cine, y es que el cine le roba ideas a la vida y, viceversa, ella hace lo propio.

El realizador cinematográfico encuentra en lo cotidiano, en el suyo y el ajeno, la materia prima para sus relatos: advierte, examina, asimila y aprende a manipular los puntos de confluencia entre la realidad y la ficción, entre la vida, el sueño, la ensoñación y los delgados velos del ser, estar y hacer del hombre como reflejo del personaje y viceversa. Cada proyección fílmica ofrece al espectador la posibilidad de iniciar un viaje hacia lo inexplorado, que puede desembocar en la observación de territorios geográficos lejanos, o bien, en un complicado pero excitante juego de espejos donde el espectador se disuelve, se desprende de su cuerpo, se funde con la pantalla y entra, sin desearlo siquiera, en una dimensión que en apariencia, solo en apariencia, no le corresponde. 
Para los habitantes del siglo XXI, la convivencia con el universo de la imagen en movimiento pudiera resultar impensable; el cine, además de tener una función catártica, constituye la visión de ese gran otro que nos confronta con nuestros miedos, deseos y contradicciones, pues como apunta Francesco Casetti, existe entre el relato fílmico y la realidad psíquica del espectador "(...) una estrecha consanguineidad" que se aprecia en "los desarrollos y los temas que surgen continuamente en él" (Casetti, 2000, p. 189).

\section{La seducción de la imagen}

El encanto y la adoración que provoca la imagen guarda íntima relación con la posibilidad de representar lo ausente, de ahí que sea tan apreciada la imagen fotográfica de un ser que ha dejado este mundo. La imagen mental es ordenación cardinal de la conciencia, tanto la presencia del mundo en el hombre como la del hombre en el mundo están empapadas por su representación, se trata de una dualidad inacabada y constantemente transmutada de las presencias: "la imagen no es más que un doble, un reflejo, es decir, una ausencia" (Morin, 2001, p. 30). Una imagen constituye la posibilidad de desprender la presencia misma del sujeto u objeto original para reencarnarlo en su representación. Así, el hombre guarda en su memoria representaciones de los ausentes, figuras simbólicas que encarnan la presencia de lo que no está, de lo que se ha ido o de lo que nunca estuvo; a esto se le conoce, en primera instancia, como visión mental.

En el universo de lo imaginable, solo está lo que se ve o lo que posee una factible representación mental de lo que pudiera ser; todo aquello que no ostente posibilidad de representación produce temor $\mathrm{y}$, entonces, obliga a materializar la turbación para dotarla de una posible imagen, aunque resulte desagradable. El cine, desde su alumbramiento, se mostró como un artilugio capaz de representar la realidad de las imágenes con una franqueza jamás imaginada, sedujo a sus espectadores y los enganchó hasta hacerlos suyos.

Con el paso del tiempo, como si de una caja de Pandora se tratara, el cine se abrió para dejar escapar las ilusiones más extraordinarias destinadas a volar entre los hombres, pero también dio pie a la representación de lo que en otras narrativas resultaba inefable. 
Filosofía, tecnología y cultura...

La puesta en escena de lo monstruoso, de lo deforme, de lo horroroso, comenzó a ocupar un lugar inédito en la historia, pues como afirma José Luis Barrios, sus representaciones adquirieron "un valor y un sentido contrario a los cánones estéticos y artísticos de la modernidad" (Barrios, 2010, p. 27).

Desde su aparición, el cinematógrafo confesó su naturaleza de espectáculo: George Méliès supo detectar, explorar y echar a volar su potencial iniciando una revolución en el mundo de la imagen pues, según lo apunta G. Sadoul (como se citó en Morin, 2001), las formulitas de Méliès “ (...) constituyeron en realidad el germen de la sintaxis, del lenguaje, de los medios de expresión del cine"; y así, desde 1897, Méliès transfigura a una máquina que hasta ese momento había sido fabricante de meras realidades, en un artefacto asociado con la fantasmagoría; un fenómeno que alcanzaría momentos cumbre, más adelante, en el trabajo de Tod Browning (Drácula, Freaks, Mark of the Vampire) James Whale (Frankenstein, The Invisible Man) Ridley Scott, George A. Romero, George Lucas, Steven Spielberg e incluso el mismo Stanley Kubrick, quienes con su obra ayudaron a configurar el imaginario de lo que hoy entendemos como cine de ciencia ficción.

En la narrativa de la ciencia ficción confluyen tres elementos interesantes, una relación tejida a manera de trenza a distintos niveles entre comunicación, cultura y tecnología. Primero, desde la propia existencia del cine como medio de comunicación, segundo, a partir de la configuración discursiva implícita que se manifiesta de acuerdo con las posibilidades tecnológicas de cada época y, por último, mediante la recepción-apropiación del espectador respecto al relato y sus connotaciones ocultas.

En la ciencia ficción se pueden encontrar también narraciones que especulan con hipótesis extrapoladas con base en ideas prematuras del mundo actual como forjador del venidero, a partir del uso de una imaginativa más o menos proyectada en la situación vigente, ya sea en el ámbito de la ciencia, la tecnología o las visiones sociales a futuro; a este tipo de historias se le cataloga como realidad posible. El discurso de la obra se fija en la posibilidad de que " $\mathrm{x}$ " o " $\mathrm{y}$ " suceda con base a las expectativas y proyecciones "reales" de los elementos sociopolíticos, comunicativo-culturales y tecnocientíficos del momento histórico en que son planteados. 


\section{La odisea espacial}

Pocas veces el cine de ciencia ficción ha brindado al espectador un regalo visual e intelectual tan valioso como en el caso de 2001: una odisea del espacio (EUA, 1968) de Stanley Kubrick. Mediante la condensación brutal de la evolución biocultural del hombre, manifestada a través de una alegórica mutación entre un hueso volador y una nave espacial, 2001: una odisea del espacio abre paso hacia una experiencia estética, sensorial e intelectual emotivamente intransferible. La cinta invita al espectador a la reflexión introspectiva micro y macro cósmica respecto al espíritu, las capacidades epistémicas y la sociedad misma a través de múltiples niveles de significación.

En una primera aproximación que parece referirse a la teoría de la evolución de Darwin, en la cual se considera al mono como antepasado del hombre, hay una visión optimista. El surgimiento de la herramienta como primer signo de inteligencia pero también de progreso; sin embargo, esta misma herramienta se manifestará tarde o temprano como lo que Heidegger denomina la "esencia de la técnica", es decir, lo que hace perceptible lo real y efectivo al hacer salir "lo oculto" que pone al hombre en un camino ante el cual se le conoce como el sino o lo destinado (Heidegger, 2007, p. 27).

En "El amanecer del hombre" este se encuentra representado por una unidad secuencial donde el mono, como primate gregario primitivo y nómada, tiene que economizar sus recursos debido a la falta de medios para la obtención de satisfactores. Aquí aparece por primera vez el monolito (¿una herramienta del futuro?) tras cuya inspección el mono es redimido y ascendido a una categoría más digna: el Homo Faber, el creador, el manipulador de la naturaleza, el futuro amo del universo.

El destino del hombre, desde la visión de Kubrick, se encuentra envuelto en una especie de determinismo autopoiético, que se hace patente en la transformación de la primera herramienta, un hueso que metafóricamente alude al fuego de Prometeo, en un arma que revira y atenta contra la vida de un semejante. 
Filosofía, tecnología y cultura...

El asesinato se muestra como la primera implicación por medio de la cual el director advierte sobre la doble articulación del objeto técnico, como extensión de la capacidad creativa del hombre, pero también como mecanismo de destrucción, se muestra como el punto de partida de un proceso histórico en el cual "lo oculto" heideggeriano se hace presente como peligro.

Sin embargo, aquel hueso que, al finalizar la primera parte, vuela hacia los aires transformándose en una nave que danza en la inmensidad del espacio es también una alegoría de lo que el filósofo alemán, en su texto La pregunta por la técnica, advierte cuando dice que:

Sea cual sea el modo como prevalece el sino del hacer salir lo oculto, el estado de desocultamiento en el que se muestra cada vez todo lo que es, alberga el peligro de que el hombre se equivoque con lo no oculto y lo malinterprete (Heidegger, 2007, p. 29)

Así, el amanecer del hombre como un metarrelato sobre el fuego nuevo y la prosperidad de la especie para buscar el bien, se ve opacado por la visión perversa de lo que pudiera ser la primera muerte violenta, como detonador del "progreso" que estaba por venir. La máquina, la aeronave, y posteriormente el robot, una versión más avanzada de esa primera herramienta, autoconsciente $\mathrm{y}$, por ende, poseedora de un instinto de preservación, aniquila a los tripulantes de una nave miles de años en el futuro. La inteligencia artificial, aquella tecnología creada por la humanidad para facilitarle la vida, para ser una compañera que se adaptaría a las necesidades y labores de su creador, se torna hostil, aludiendo nuevamente al comienzo de la cinta, en donde aquellas extensiones del cuerpo que menciona McLuhan, se vuelven contra él.

En la segunda parte de la cinta, la idea anterior se diluye ligeramente. Kubrick muestra al hombre, en palabras de Nietzsche (2004), como el explorador intergaláctico que ha conquistado su voluntad. En esta segunda parte, plagada de secuencias contemplativas, la voluntad del poder se evidencia como una corriente profunda, dinámica, creadora y transformadora que vitaliza todo. En uno de los viajes interestelares, el monolito es nuevamente localizado en la luna y funge como testigo silencioso de la evolución. 
El hombre ya no es un primate inferior que construye herramientas arcaicas, sino que ha diseñado sofisticados artefactos para expandir sus posibilidades comunicativoculturales-tecnológicas.

Kubrick pretendía con su trabajo mostrar una aproximación a la posible realidad del año 2001, y para ello realizó una exhaustiva investigación en la cual fue asesorado por especialistas de diversas áreas. Sin embargo, uno de los aspectos más memorables de la película se encuentra en el tercer capítulo: HAL, la computadora con la cual el mito del robot se relaciona con las rutas del inconsciente en pos de dominio del objeto. HAL es un microcosmos alegórico que sustituye simultáneamente al hombre y al mundo; es una síntesis entre el antropomorfismo y la funcionalidad absoluta que surge de la quimera creadora (la voluntad como posibilidad vitalizante de Shopenhauer) que se coloca al nivel de creador-dios y construye un esclavo a su imagen y semejanza, supuestamente, sin perspectivas de evolución, pero con la posibilidad inherente hacia la insurrección.

HAL ha alcanzado tal nivel de humanización que logra no solo ejercer su memoria, sino también tomar decisiones, posee sentimientos y emociones, e incluso, llega a cuestionar al hombre (como el hombre mismo cuestiona a su dios-creador) acerca de su gradual deshumanización y falta de sentimientos. HAL, debido a su "naturaleza" heurística, decide matar en defensa propia, sí, pero este acto también pone de manifiesto que si la máquina es un apéndice de las funciones humanas y de su conciencia, encuentra en esta decisión el único camino para salvaguardar sus intereses y su permanencia.

Aún así, HAL pasa por alto que es el creador quien conoce su esencia y por ende sus debilidades. Al final, la superioridad del gran arquitecto, representado por David Bowman, único sobreviviente, prevalece, lo cual le permite, a su vez, encumbrarse más adelante hacia el conocimiento profundo del universo para renacer en él.

Desde otro enfoque, 2001: una odisea del espacio se puede dividir en una trinidad: una serie de capítulos representados por las etapas de la triple transformación hacia el superhombre de Nietzsche (2004). 
Filosofía, tecnología y cultura...

La división original propuesta por el filósofo es "la triple transformación hacia el superhombre": a) Camello, donde el espíritu del hombre se representa con un camello como animal de carga que obedece y es humillado si protestar, b) León, donde el hombre que es camello se cansa y se rebela contra su amo y lo derrota, aplica su voluntad y se hace dueño de su poder creador, c) Niño, aquí, el niño se convierte en el superhombre y comienza todo de nuevo.

En la cinta estrenada en 1968, se muestra una primera etapa donde resalta la resignación del primate arcaico que debe luchar por la supervivencia en dependencia total con su entorno (camello), en la segunda se muestra la rebelión y la exploración de un espíritu que conquista su libertad creadora y se ve al hombre acompañado de su ciencia y su tecnología revoloteando por el espacio intergaláctico (león) y al final se muestra el nuevo comienzo: el nacimiento del superhombre, representado por un niño que emerge entre el espacio.

\section{Conclusiones}

El cine, desde su actitud de observador y reproductor histórico, puede dar cuenta de los factores, ramificaciones y características de todo tipo de sucesos, puede ilustrar las distintas etapas por las que ha pasado el hombre, etapas que sugieren peculiaridades geográficas, políticas, económicas, religiosas, culturales, comunicacionales o científicas de cada grupo.

El hermeneuta Schleiermarcher dice que una obra de arte no solo ayuda a reconocer hechos históricos, también induce al receptor hacia un intento de reconstrucción imaginativa de lo que el autor quiso decir, donde la intencionalidad juega un papel fundamental; al interpretar, muchas veces, rebasamos lo que en realidad insinuaba el creador.

Resulta importante aclarar que para que una obra fílmica pueda fungir como un documento histórico digno, es menester retratar, lo más cercano a la realidad, tanto escenarios (abarcando tiempo y espacio) como personajes, acciones y lenguaje; esto no quiere decir que se pugne únicamente por la producción de películas de género histórico o de época: cualquier cinta, sea cual sea su tema, estará confesando las inquietudes y modos de ser, estar, hacer, pensar y hablar de un momento determinado. 
El cine ha retratado incansablemente sucesos históricos y sus consecuencias en la psique colectiva. La relación que ha sostenido el cine con este tipo de eventos se dirige hacia distintos rumbos, por un lado, elabora un testimonio de los sucesos y desde ahí, puede fungir incluso como fiscal acusador. Un ejemplo de ello apunta hacia los documentales que se realizaron sobre los campos de exterminio nazi, los cuales sirvieron como pruebas para condenar a algunos culpables. La industria cinematográfica también puede llegar a ser cómplice de las manipulaciones ideológicas y soporte de nacionalismos enardecidos que dirigen a sus ciudadanos al combate.

En el caso de la obra fílmica que ha sido tratada en este documento es evidente que no se reflejan pasajes de una historia comprobada, más bien, se expone una de las muchas explicaciones que hay sobre nuestra presencia y ruta en el universo. La ciencia ficción aspira a elaborar un retrato sobre los alcances y consecuencias de la tecnología, la sociedad, la cultura y la ciencia misma que proporcione un panorama sobre las rutas que la humanidad debe seguir o evitar.

\section{Referencias}

Abbagnano, N. (2000). Diccionario de Filosofía. México: Fondo de Cultura Económica.

Barrios, J. (2010). El cuerpo disuelto. Lo colosal y lo monstruoso. México: Universidad Iberoamericana.

Bunge, M. (2000). Epistemología. México: Siglo XXI Editores.

Casetti, F. (2000). Teorías del cine. España: Editorial Cátedra.

Darwin, C. (1963). El origen de las especies por la selección natural. España: Ediciones Ibéricas. 
Filosofía, tecnología y cultura...

Heidegger, M. (2007). La pregunta por la técnica (y otros textos). Barcelona, España: Ediciones Folio.

Kroeber, A. y Kluckhohn, C. (1959). Culture: A Critical Review of Concepts and Definitions. USA: A Vintage Book. A Division of Random House.

Kubrick, S. (productor y director). (1968). 2001: una odisea del espacio [cinta cinematográfica]. Estados Unidos y Reino Unido: Metro Goldwyn Mayer Studios.

Lage Dávila, A. (2001). La ciencia y la cultura: las raíces culturales de la productividad. Revista Educación Médica Superior. 15(2), 189-205. Recuperado de http://scielo.sld.cu/pdf/ems/v15n2/ems08201.pdf

Maturana, H. (2003). Desde la Biología a la Psicología. Argentina: Grupo Lumen.

McLuhan, M. (1996). Comprender los medios de comunicación. Las extensiones del ser humano. México: Paidós.

McLuhan, E. y McLuhan, M. (1990). Leyes de los medios. La nueva ciencia. México: Paidós.

Morin, E. (2001). El cine o el hombre imaginario. Barcelona: Paidós.

Morin, E. (2009). El Método 5. La humanidad de la humanidad. La identidad humana. Madrid: Ediciones Cátedra.

Nietzsche, F. (2004). Así habló Zaratustra. México: Porrúa.

Sadoul, G. (1998). Historia del cine mundial, desde los orígenes. México: Siglo XXI. 